\title{
Prevalence and risk factors of anemia among children aged 6-23 months in Huaihua, Hunan Province
}

\author{
Zhi Huang $^{1^{*}}$ (D), Fu-xiang Jiang ${ }^{2}$, Jian $\mathrm{Li}^{2}$, Dan Jiang ${ }^{2}$, Ti-gang Xiao ${ }^{2}$ and Ju-hua Zeng ${ }^{2}$
}

\begin{abstract}
Background: Anemia is one of the most common diseases of childhood and is a health problem globally, particularly in developing counties and in children less than 2 years of age. Anemia during childhood has short- and long-term effects on health. However, few studies have investigated the prevalence of anemia among children in Huaihua. Therefore, this study analyzed the prevalence and risk factors of anemia among children 6 to 23 months of age in Huaihua.

Methods: This cross-sectional study was conducted at a maternal and child health care hospital in Huaihua, from September to November 2017. The study population recruited using a multistage sampling technique. A structured questionnaire was used to collect data on the characteristics of the children and members of their families. Hemoglobin $(\mathrm{Hb})$ levels were measured by using a microchemical reaction method. Logistic regression analysis was used to identify associated factors and odds ratio with $95 \% \mathrm{Cl}$ was computed to assess the strength of association.
\end{abstract}

Results: In total, 4450 children were included in this study. The prevalence of anemia was $29.73 \%$. In multivariate logistic regression analysis, the results show that mother and father of Miao ethnicity $(\mathrm{OR}=1.23$ and 1.31), diarrhea in the previous 2 weeks $(O R=1.35)$, breastfeeding in the prior $24 \mathrm{~h}(\mathrm{OR}=1.50)$, and caregivers able to identify the optimum timing of complementary feeding $(\mathrm{OR}=1.15)$ had positive correlations with anemia. However, children aged 18 to 23 months $(\mathrm{OR}=0.55)$, father of Dong ethnicity $(\mathrm{OR}=0.82)$, addition of milk powder once or twice $(\mathrm{OR}=0.71)$, addition of infant formula once or twice, three times, and four or more times in the previous $24 \mathrm{~h}(\mathrm{OR}=0.72,0.70$, and 0.75$)$, and addition of a nutrient sachet four or more times in the prior week $(O R=0.70)$ were negatively associated with anemia.

Conclusions: The prevalence of anemia among children 6 to 23 months of age in Huaihua was higher than that in more developed regions of China. The feeding practice of caregivers was associated with anemia. nutrition improvement projects are needed to reduce the burden of anemia among children in Huaihua.

Keywords: Risk factors, Anemia, Children

\section{Background}

Anemia is one of the most common diseases of childhood and is a health problem globally, particularly in developing counties and in children less than 2 years of age [1, 2]. From 1993 to 2005, the global prevalence of anemia was $47.4 \%$ among children less than 5 years of age, and $46-66 \%$ in developing countries [3, 4]. In China in 2012, 28.2 and $20.5 \%$ of children $6-12$ and $13-24$ months of age, respectively, had anemia [5].

\footnotetext{
* Correspondence: hhsfbyzhige@hotmail.com

${ }^{1}$ Hunan University of Medicine, No. 492 Jinxi South Road, Huaihua 418000,

Hunan, China

Full list of author information is available at the end of the article
}

Anemia during childhood has short- and long-term effects on health. The former include an increased risk of morbidity due to infectious disease $[4,6,7]$. In addition, anemia during childhood is strongly associated with neurological development, and cognitive and immune function, and can lead to mental impairment and poor motor development $[8,9]$. The long-term effects include reduced academic achievement and work capacity in adulthood $[7,10]$.

The majority of related studies show that anemia during childhood is strongly associated with food intake [11, 12]. Others reveal that economic status [13], residence in an urban or rural area [14], caregiver's educational level [7], fever and diarrhea [15], low birth weight [7], 
and insufficient nutrition [15] are related to anemia during childhood.

The government of China provides nutrient sachets to children aged 6 to 23 months in poor areas of China, which has dramatically decreased the prevalence of anemia in children in western China [16, 17]. However, few studies have investigated the prevalence of anemia, or the effect of the nutrient sachet program thereon, among children in Huaihua.

Therefore, this cross-sectional study analyzed the prevalence and risk factors of anemia among children 6 to 23 months of age in Huaihua. Our findings will enable the development of countermeasures to reduce the burden of anemia and promote the health of children.

\section{Materials and methods}

\section{Study design and area}

This cross-sectional study was conducted at a maternal and child health care hospital in Huaihua, the largest city in midwestern China, from September to November 2017. The population of Huaihua in 2017 was 5,450,289, of which 322,876 were children under 5 years of age. A nutrient sachet program has been implemented in Huaihua since 2012.

\section{Study population and sampling techniques}

The study population consisted of caregivers and their children 6 to 23 months of age in seven rural regions of Huahuai recruited using a multistage sampling technique. Initially, the 13 regions of Huaihua line up according income, 7 rural regions were selected according income. Secondly, all towns of each region line up according income, ten towns were selected at random in each region. Then all villages of each town line up according income, three to five villages were selected at random in each town. According to the total number of live births, three villages were selected in Zhijiang and Huitong, four villages in Xinghuang, and five villages in Yuangling, Xupu, Mayang, and Chenxi. In total, 300 villages were selected. All children 6 to 23 months of age in each village line up according date of birth and 15 children 6 to 23 months of age in each village were selected by systematic random sampling, for a total of 4500 children (See Fig. 1). Income data were obtained from the 2016 Huaihua Statistical Yearbook and the number of live births from the 2016 Child Annual Report.

\section{Data collection}

A structured questionnaire was used to collect data on the demographic characteristics of the children and members of their families, as well as the children's health status, feeding practice in the previous $24 \mathrm{~h}$, and the caregivers' level of knowledge of nutrition. Information on the children's health status included gestational age, birth weight, and any episode of fever or diarrhea in the previous 2
Step1: seven rural regions were selected according income from the thirteen regions of Huaihua

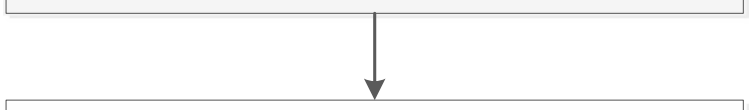

Step2: ten towns were selected at random in each region according income

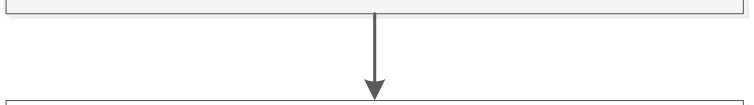

Step3: according to the total live birth number of local area, three to five villages were selected at random in each town.

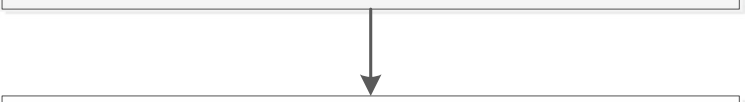

Step4:15 children aged 6 to 23 months were selected in each village by Systematic Random Sampling, according date of birth

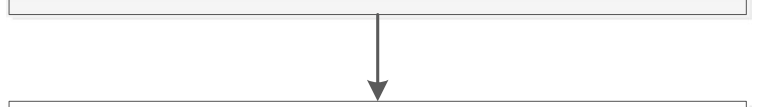

Step5: 4500 children were selected.

Fig. 1 The flow chart of the sampling process

weeks. The questionnaire was designed by the Chinese Center for Disease Control and Prevention to assess pilot projects for improving child nutrition in poverty-stricken areas of China. Hemoglobin $(\mathrm{Hb})$ levels were measured in the fingertip peripheral blood of the children using a microchemical reaction method and Hemocue 301 instrument (Hemocue AB, Sweden), and were expressed as $\mathrm{g} /$ dL. Blood samples were collected in local public health centers. Anemia was assessed based on the criteria of Pediatrics, seventh edition published by the People's Medical Publishing House. The cut-off point for anemia for children 6 to 23 months of age was $<11.0 \mathrm{~g} / \mathrm{dL} \mathrm{Hb}$.

\section{Statistical analysis}

Data were cleaned, coded, and entered using Epidata 3.1 and analyzed by Statistical Product and Service Solutions 13. A descriptive analysis was performed to summarize the data, followed by bivariate logistic regression analyses of caregivers' ethnicity, educational level, occupations, group, and level of knowledge of nutrition, as well as the age, sex, preterm birth, low birth weight, episode 
of diarrhea or fever in the previous 2 weeks, and food intake in the prior $24 \mathrm{~h}$ of the children. Factors with a value of $P \leq 0.10$ in a bivariate analysis were included in the multivariable stepwise logistic regression model. Odds ratios (ORs) with 95\% confidence intervals (CIs) were calculated to determine the strength of associations. A value of $P<0.05$ was considered indicative of statistical significance.

\section{Ethics approval and consent to participate}

Informed consent was signed by the caregivers of the children prior to their being interviewed. The project complies with national guidelines and does not involve personal privacy. The project was approved by Huaihua Women's Federation and Municipal Commission of Health and Family Planning (No. 201563).

\section{Results}

\section{Demographic characteristics and health status}

In total, 4450 children were included in this study. Fifty children whose caregivers refused to be interviewed were excluded (collection rate, $98.88 \%$ ). The characteristics of the 4450 children are listed in Table 1 . The prevalence of anemia was $29.73 \%$. The educational level of $>70 \%$ of the parents/caregivers was under senior. The parents of almost $50 \%$ of the children were of Han ethnicity. The majority of the mothers and caregivers were homemakers (48.74 and $99.64 \%$, respectively). Of the caregivers of the children, $61.71 \%$ were their mothers. The incidences of premature birth and a low birth weight were less than $5 \%$. Of the children, 18.58 and $12.20 \%$ reported that they had experienced fever and diarrhea in the previous 2 weeks (Table 2).

\section{Feeding practice and nutrition knowledge}

In the previous $24 \mathrm{~h}$, most of the children had consumed water, soup, rice soup (92.45\%), and solid/semisolid food (92.61\%), but only $6.94 \%$ had consumed yogurt. Of the children, $31.03 \%$ had consumed infant formula once or twice and $48.85 \%$ had consumed a nutrient sachet four times or more in the prior week (Table 3). Of the caregivers, $44.20 \%$ could identify the optimum timing of complementary feeding but only $5.06 \%$ could identify the first complementary food which should be consumed by infants (Table 4 ).

\section{Bivariate logistic regression analyses}

Table 5 shows the results of bivariate logistic regression analyses of anemia among children 6 to 23 months of age. Compared to children 6 to 11 months of age, the prevalence of anemia was lower among those 12 to 17 and 18 to 23 months of age $(\mathrm{OR}=0.64,0.39$ and $P<$ $0.001,<0.001$, respectively). Compared to children with Han mothers and fathers, the prevalence of anemia was higher in those with Miao mothers and fathers $(\mathrm{OR}=1.46$, 1.44 and $\mathrm{P}<0.001,<0.001$, respectively) and lower in children with Dong mothers and fathers $(\mathrm{OR}=0.80,0.80$ and $P=0.010,0.007$, respectively). Compared to the children of homemaker mothers, those of mothers employed in the professions, commerce, as equipment operators, and other occupations had a lower risk of anemia $(\mathrm{OR}=0.70,0.65$, $0.61,0.60$ and $P=0.072,0.008,0.073,<0.001$, respectively). Compared to the children of homemaker fathers, those of fathers employed in animal husbandry and fishery, and others had a lower risk of anemia $(\mathrm{OR}=0.85$, 0.81 and $P=0.085,0.038$, respectively). Compared to children cared for by their mothers, those cared for by their father or grandparents had a lower prevalence of anemia ( $\mathrm{OR}=0.46,0.59$ and $P=0.050,<0.001$, respectively). In addition, female gender $(\mathrm{OR}=0.89, P=0.078)$, mothers and fathers' education to university level $(\mathrm{OR}=0.65,0.70$, and $P=0.016,0.046$, respectively) were associated with a lower risk of anemia. Diarrhea in the previous 2 weeks was also correlated with anemia $(\mathrm{OR}=1.50, P<0.001)$.

Breastfeeding in the past $24 \mathrm{~h}$ was correlated with anemia $(\mathrm{OR}=2.30, \mathrm{P}<0.001)$. Compared to children who did not consume a sugary drink in the past $24 \mathrm{~h}$, those who did consume a sugary drink had a decreased risk of anemia $(\mathrm{OR}=0.79, P=0.001)$. Compared to no addition of infant formula in the past $24 \mathrm{~h}$, addition of infant formula once or twice, three times, and four times or more decreased the risk of anemia $(\mathrm{OR}=0.56,0.59$, 0.73 and $\mathrm{P}<0.001,<0.001,0.004$, respectively). Compared to no addition of milk powder in the past $24 \mathrm{~h}$, addition of milk powder once or twice decreased the risk of anemia $(\mathrm{OR}=0.60, \quad P<0.001)$. Compared to no addition of a nutrient sachet in the previous week, addition of a nutrient sachet once or twice increased the risk of anemia $(\mathrm{OR}=1.26, P=0.071)$, while addition of a nutrient sachet four or more times decreased the risk of anemia $(\mathrm{OR}=0.071, P<0.001)$. The ability of caregivers to identify the optimum timing of complementary feeding was significantly associated with anemia $(\mathrm{OR}=1.20$, $P=0.007)$.

\section{Multivariate logistic regression analysis}

All variables with $P<0.10$ in bivariate logistic regression analyses were entered into the multivariate logistic regression analysis (Table 6). Compared to children 6 to 11 months of age, the risk of anemia among those 18 to 23 months of age decreased by $45 \%(\mathrm{OR}=0.55, P<0.001)$. Compared to children with Han mothers, those with Miao mothers had a 1.23-fold increased risk of anemia $(\mathrm{OR}=$ 1.23, $P=0.044)$. Compared to children with Han fathers, those with Miao fathers had a 1.31-fold increased risk of anemia $(\mathrm{OR}=1.31, P=0.013)$ and those with Dong fathers had an $18 \%$ decreased risk $(\mathrm{OR}=0.82, P=0.047)$. Having 
Table 1 The demographic characteristic of children 6 to 23 months of age $(n=4450)$

\begin{tabular}{|c|c|c|c|c|c|}
\hline Characteristic & Frequencies & Percent (\%) & Characteristic & Frequencies & Percent (\%) \\
\hline Sex & & & Fathers & 42 & 0.94 \\
\hline Boys & 2345 & 52.70 & Grandparents & 1651 & 37.10 \\
\hline Girls & 2105 & 47.30 & Others & 11 & 0.25 \\
\hline Age & & & Caregiver's educational level & & \\
\hline $6 \sim 11$ months & 1536 & 34.52 & Primary & 3243 & 72.88 \\
\hline 12 17 months & 1411 & 31.71 & Junior & 938 & 21.08 \\
\hline $18 \sim 23$ months & 1503 & 33.78 & Senior & 257 & 5.78 \\
\hline Mother's ethnicity & & & University & 12 & 0.27 \\
\hline Han & 2219 & 49.87 & Caregiver's occupation & & \\
\hline Dong & 991 & 22.27 & Professionals & 16 & 0.36 \\
\hline Miao & 1012 & 22.74 & Homemakers & 4434 & 99.64 \\
\hline Others & 228 & 5.12 & Anemia status & & \\
\hline Mother's educational level & & & Normal & 3127 & 70.27 \\
\hline Primary & 409 & 9.19 & Anemia & 1323 & 29.73 \\
\hline
\end{tabular}

Junior

Senior

University

Mother's occupation

Homemakers

Professionals

Commerce

Animal husbandry and fishery

Operators equipment

Others

Father's ethnicity

$\begin{array}{ll}\text { Han } & 2133 \\ \text { Dong } & 112 \\ \text { Miao } & 1007 \\ \text { Others } & 190\end{array}$

Father's occupation

Homemakers

Professionals

Commerce

Animal husbandry and fishery

Operators equipment

Others

Father's educational level

Primary

Junior

Senior

University

Caregiver's groups

Mothers
2953

828

260

2169

143

227

1225

66.36

18.61

5.84

48.74

3.21

5.10

27.53

1.78

13.64

47.93

25.17

22.63

4.27

190

791

316

350

1678

305

1010

326

2957

858

309

2746
Table 1 The demographic characteristic of children 6 to 23 months of age $(n=4450)$ (Continued)

diarrhea in the previous 2 weeks increased the risk of anemia 1.35 -fold (OR $=1.35, P=0.003)$.

Children not breastfed in the past $24 \mathrm{~h}$ had a 1.50 -fold greater risk of anemia than those breastfed $(\mathrm{OR}=1.50, P<0.001)$. Addition of milk powder once or twice in the previous $24 \mathrm{~h}$ decreased the risk of anemia by $29 \%(\mathrm{OR}=0.71, P=0.005)$ compared to no addition of milk powder. Moreover, addition of infant formula once or twice, three times, and four or more times in the previous $24 \mathrm{~h}$ decreased the risk of anemia by 28,30 , and $25 \%$ compared to no addition of infant formula, respectively $(\mathrm{OR}=0.72,0.70,0.75$ and $P<0.001,0.001,0.020$, respectively). Addition of a nutrient sachet four or more times in the previous week decreased the risk of anemia by $30 \%(\mathrm{OR}=0.70$,

Table 2 Health status of children 6 to 23 months of age $(n=$ 4450)

\begin{tabular}{lll}
\hline Characteristic & Frequencies & Percent (\%) \\
\hline $\begin{array}{lll}\text { Gestational age } \\
\text { Term }\end{array}$ & 4270 & 95.96 \\
Premature & 180 & 4.04 \\
Birth weight & & \\
Normal & 4279 & 96.16 \\
Low birth weight & 171 & 3.84 \\
Fever in the previous 2 weeks & & \\
No & 3623 & 81.42 \\
Yes & 827 & 18.58 \\
Diarrhea in the previous 2 weeks & & \\
No & 3907 & 87.80 \\
Yes & 543 & 12.20 \\
\hline
\end{tabular}


Table 3 Feeding practice of children 6 to 23 months of age in the previous $24 \mathrm{~h}(n=4450)$

\begin{tabular}{lll}
\hline Feeding Practice & Frequencies & Percent (\%) \\
\hline Breastfeeding & & \\
No & 3205 & 72.02 \\
Yes & 1245 & 27.98
\end{tabular}

Consume water, soup, rice soup

$\begin{array}{ll}\text { No } & 336 \\ \text { Yes } & 4114 \\ \text { Consume sugary drink } & \\ \text { No } & 3160 \\ \text { Yes } & 1290\end{array}$

Consume infant formula and frequencies

0
1 to 2
3
4 or more
Consume milk powder and
requencies
0
1 to 2
3
4 or more

Consume yoghourt and frequencies

1 to 2
3
4 or more

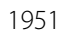

1381

613

505

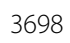

474

161

\section{1}

279

12

18

7.55

92.45

\section{4}

(1)

71.01

28.99

Consume solid/ semisolid

food and frequencies

1 to 2
3
4 or more

\section{9}

1289

43.84

31.03

13.78

11.35

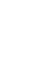

83.10

10.65

3.62

2.63

Consume nutrient sachet and frequencies*

\begin{tabular}{lll}
0 & 1773 & 39.84 \\
1 to 2 & 302 & 6.79 \\
3 & 201 & 4.52 \\
4 or more & 2174 & 48.85 \\
\hline
\end{tabular}

*Consume nutrient sachet in the prior week

$P<0.001)$ compared to no addition of a nutrient sachet. The risk of anemia for children whose caregivers were able to identify the optimum timing of complementary feeding was 1.15 -fold higher than that of children whose caregivers were not $(\mathrm{OR}=1.15, P=$ 0.039).
Table 4 Caregivers nutrition knowledge of children 6 to 23 months of age $(n=4450)$

\begin{tabular}{|c|c|c|}
\hline Nutrition Knowledge & Frequencies & Percent (\%) \\
\hline \multicolumn{3}{|c|}{$\begin{array}{l}\text { Is able identify the optimum } \\
\text { timing of complementary } \\
\text { feeding }\end{array}$} \\
\hline No & 2483 & 55.80 \\
\hline Yes & 1967 & 44.20 \\
\hline \multicolumn{3}{|c|}{$\begin{array}{l}\text { Is able identify to the first } \\
\text { complementary food which } \\
\text { should be consumed by infants }\end{array}$} \\
\hline No & 4225 & 94.94 \\
\hline Yes & 225 & 5.06 \\
\hline \multicolumn{3}{|c|}{$\begin{array}{l}\text { Has know the optimum food } \\
\text { of supplementary iron }\end{array}$} \\
\hline No & 3185 & 71.57 \\
\hline Yes & 1265 & 28.43 \\
\hline \multicolumn{3}{|c|}{$\begin{array}{l}\text { Is able identify nutrient relate } \\
\text { to anemia }\end{array}$} \\
\hline No & 2522 & 56.67 \\
\hline Yes & 1928 & 43.33 \\
\hline \multicolumn{3}{|c|}{$\begin{array}{l}\text { Is able identify the optimum } \\
\text { timing of breastfeeding }\end{array}$} \\
\hline No & 3852 & 86.56 \\
\hline Yes & 598 & 13.44 \\
\hline
\end{tabular}

\section{Discussion}

Our findings revealed that almost 30\% of children 6 to 23 months of age in Huaihua were anemic. The prevalence of anemia in our study is higher than the $4.54 \%$ of children under 2 years of age in Beijing [18], but lower than that in western rural areas of China (>30\%), such as $37.84 \%$ among children under 3 years of age in rural Tibet [19] and $64.7 \%$ among children 6 to 35 months of age in Yushu, Qinghai Province [20]. By contrast, the prevalence of anemia in children globally is $43 \%$, and approximately $70 \%$ in Central and West Africa [21]. The burden of anemia in developed counties is much lower; $7-9 \%$ of children 1 to 3 years of age in the US [22] and 2-9\% of children 6 to 39 months of age in Europe [23] are anemic.

In further analysis, the results show that mother and father of Miao ethnicity $(\mathrm{OR}=1.23$ and 1.31$)$, diarrhea in the previous 2 weeks $(\mathrm{OR}=1.35)$, breastfeeding in the prior $24 \mathrm{~h}(\mathrm{OR}=1.50)$, and caregivers able to identify the optimum timing of complementary feeding $(\mathrm{OR}=1.15)$ had positive correlations with anemia. However, children aged 18 to 23 months (OR $=0.55)$, father of Dong ethnicity $(\mathrm{OR}=0.82)$, addition of milk powder once or twice in the prior week $(\mathrm{OR}=0.71)$, addition of infant formula once or twice, three times, and four or more times in the previous $24 \mathrm{~h}(\mathrm{OR}=0.72,0.70$, and 0.75$)$, and addition of a nutrient sachet four or more times in the prior week $(\mathrm{OR}=0.70)$ were negatively associated with anemia. 
Table 5 Bivariate regression analysis of anemia among children 6 to 23 months of age

\begin{tabular}{|c|c|c|c|c|c|}
\hline Parameters & $\mathrm{N}$ & $n$ & (\%) & OR(95\%Cl) & $P$ value \\
\hline \multicolumn{6}{|l|}{ Sex } \\
\hline Boy & 2345 & 724 & 30.87 & 1 & \\
\hline Girl & 2105 & 599 & 28.46 & $0.89(0.78,1.10)$ & 0.078 \\
\hline \multicolumn{6}{|l|}{ Age } \\
\hline $6 \sim 11$ months & 1536 & 604 & 39.32 & 1 & \\
\hline 12 17 months & 1411 & 414 & 29.34 & $0.64(0.55,0.75)$ & $<0.001$ \\
\hline 18 23 months & 1503 & 305 & 20.29 & $0.39(0.33,0.46)$ & $<0.001$ \\
\hline \multicolumn{6}{|l|}{ Mother's ethnicity } \\
\hline Han & 2219 & 637 & 28.71 & 1 & \\
\hline Dong & 991 & 241 & 24.32 & $0.80(0.67,0.95)$ & 0.010 \\
\hline Miao & 1012 & 374 & 36.96 & $1.46(1.24,1.70)$ & $<0.001$ \\
\hline Others & 228 & 71 & 31.14 & $1.12(0.84,1.51)$ & 0.440 \\
\hline \multicolumn{6}{|l|}{ Mother's educational level } \\
\hline Primary & 409 & 133 & 32.52 & 1 & \\
\hline Junior & 2953 & 879 & 29.77 & $0.88(0.70,1.10)$ & 0.256 \\
\hline Senior & 828 & 249 & 30.07 & $0.89(0.69,1.15)$ & 0.381 \\
\hline University & 260 & 62 & 23.85 & $0.65(0.46,0.92)$ & 0.016 \\
\hline \multicolumn{6}{|l|}{ Mother's occupation } \\
\hline Homemakers & 2169 & 704 & 32.46 & 1 & \\
\hline Professionals & 143 & 36 & 25.17 & $0.70(0.48,1.03)$ & 0.072 \\
\hline Commerce & 227 & 54 & 23.79 & $0.65(0.47,0.89)$ & 0.008 \\
\hline Animal husbandry and fishery & 1225 & 376 & 30.69 & $0.92(0.79,1.07)$ & 0.290 \\
\hline Operators equipment & 79 & 18 & 22.78 & $0.61(0.36,1.04)$ & 0.073 \\
\hline Others & 607 & 135 & 22.24 & $0.60(0.48,0.76)$ & $<0.001$ \\
\hline \multicolumn{6}{|l|}{ Father's ethnicity } \\
\hline Han & 2133 & 617 & 28.93 & 1 & \\
\hline Dong & 1120 & 274 & 24.46 & $0.80(0.68,0.94)$ & 0.007 \\
\hline Miao & 1007 & 372 & 36.94 & $1.44(1.23,1.89)$ & $<0.001$ \\
\hline Others & 190 & 60 & 31.58 & $1.13(0.82,1.56)$ & 0.441 \\
\hline \multicolumn{6}{|l|}{ Father's educational level } \\
\hline Primary & 326 & 108 & 33.13 & 1 & \\
\hline Junior & 2957 & 874 & 29.56 & $0.85(0.66,1.08)$ & 0.182 \\
\hline Senior & 858 & 261 & 30.42 & $0.88(0.67,1.16)$ & 0.369 \\
\hline University & 309 & 80 & 25.89 & $0.70(0.50,0.99)$ & 0.046 \\
\hline \multicolumn{6}{|l|}{ Father's occupation } \\
\hline Homemakers & 791 & 259 & 32.74 & 1 & \\
\hline Professionals & 316 & 102 & 32.28 & $0.98(0.74,1.29)$ & 0.882 \\
\hline Commerce & 350 & 100 & 28.57 & $0.82(0.62,1.10)$ & 0.162 \\
\hline Animal husbandry and fishery & 1678 & 492 & 29.32 & $0.85(0.71,1.10)$ & 0.085 \\
\hline Operators equipment & 305 & 85 & 27.87 & $0.79(0.59,1.06)$ & 0.120 \\
\hline Others & 1010 & 285 & 28.22 & $0.81(0.66,0.99)$ & 0.038 \\
\hline \multicolumn{6}{|l|}{ Caregiver's groups } \\
\hline Mothers & 2746 & 928 & 33.79 & 1 & \\
\hline Fathers & 42 & 8 & 19.05 & $0.46(0.21,1.00)$ & 0.050 \\
\hline
\end{tabular}


Table 5 Bivariate regression analysis of anemia among children 6 to 23 months of age (Continued)

\begin{tabular}{|c|c|c|c|c|c|}
\hline Parameters & $\mathrm{N}$ & $n$ & (\%) & OR(95\%Cl) & $P$ value \\
\hline Grandparents & 1651 & 385 & 23.32 & $0.59(0.52,0.68)$ & $<0.001$ \\
\hline Others & 11 & 2 & 18.18 & $0.43(0.09,2.02)$ & 0.288 \\
\hline \multicolumn{6}{|c|}{ Caregiver's educational level } \\
\hline Primary & 3243 & 990 & 30.53 & 1 & \\
\hline Junior & 938 & 262 & 27.93 & $0.88(0.75,1.04)$ & 0.127 \\
\hline Senior & 257 & 69 & 26.85 & $0.83(0.63,1.11)$ & 0.217 \\
\hline University & 12 & 2 & 16.67 & $0.45(0.10,2.08)$ & 0.310 \\
\hline \multicolumn{6}{|l|}{ Caregiver's occupation } \\
\hline Professionals & 16 & 2 & 12.50 & 1 & \\
\hline Homemakers & 4434 & 1321 & 29.79 & $2.97(0.67,13.08)$ & 0.150 \\
\hline \multicolumn{6}{|l|}{ Gestational age } \\
\hline Term & 4270 & 1265 & 29.63 & 1 & \\
\hline Premature & 180 & 58 & 32.22 & $1.13(0.82,1.55)$ & 0.455 \\
\hline \multicolumn{6}{|l|}{ Birth weight } \\
\hline Normal & 4279 & 1276 & 29.82 & 1 & \\
\hline Low birth weight & 171 & 47 & 27.49 & $0.89(0.63,1.26)$ & 0.513 \\
\hline \multicolumn{6}{|c|}{ Fever in the previous 2 weeks } \\
\hline No & 3623 & 1077 & 29.73 & 1 & \\
\hline Yes & 827 & 246 & 29.75 & $1.10(0.85,1.18)$ & 0.991 \\
\hline \multicolumn{6}{|c|}{ Diarrhea in the previous 2 weeks } \\
\hline No & 3907 & 1119 & 28.64 & 1 & \\
\hline Yes & 543 & 204 & 37.57 & $1.50(1.24,1.81)$ & $<0.001$ \\
\hline \multicolumn{6}{|l|}{ Breastfeeding } \\
\hline No & 3205 & 788 & 24.59 & 1 & \\
\hline Yes & 1245 & 534 & 42.89 & $2.30(2.00,2.64)$ & $<0.001$ \\
\hline \multicolumn{6}{|c|}{ Consume water, soup, rice soup } \\
\hline No & 336 & 107 & 31.85 & 1 & \\
\hline Yes & 4112 & 1215 & 29.55 & $0.90(0.71,1.14)$ & 0.377 \\
\hline \multicolumn{6}{|l|}{ Consume sugary drink } \\
\hline No & 3146 & 976 & 31.07 & 1 & \\
\hline Yes & 1290 & 343 & 26.59 & $0.79(0.69,0.91)$ & 0.001 \\
\hline \multicolumn{6}{|c|}{ Consume infant formula and frequencies } \\
\hline 0 & 1951 & 697 & 35.73 & 1 & \\
\hline 1 to 2 & 1381 & 328 & 23.75 & $0.56(0.48,0.65)$ & $<0.001$ \\
\hline 3 & 613 & 152 & 24.80 & $0.59(0.48,0.73)$ & $<0.001$ \\
\hline 4 or more & 505 & 146 & 28.91 & $0.73(0.59,0.91)$ & 0.004 \\
\hline \multicolumn{6}{|c|}{ Consume milk powder and frequencies } \\
\hline 0 & 3698 & 1145 & 30.96 & 1 & \\
\hline 1 to 2 & 474 & 101 & 21.31 & $0.60(0.48,0.76)$ & $<0.001$ \\
\hline 3 & 161 & 45 & 27.95 & $0.86(0.61,1.23)$ & 0.418 \\
\hline 4 or more & 117 & 32 & 27.35 & $0.84(0.55,1.27)$ & 0.405 \\
\hline \multicolumn{6}{|c|}{ Consume yoghourt and frequencies } \\
\hline 0 & 4141 & 1242 & 29.99 & 1 & \\
\hline 1 to 2 & 279 & 74 & 26.52 & $0.84(0.64,1.11)$ & 0.220 \\
\hline
\end{tabular}


Table 5 Bivariate regression analysis of anemia among children 6 to 23 months of age (Continued)

\begin{tabular}{|c|c|c|c|c|c|}
\hline Parameters & $\mathrm{N}$ & $n$ & (\%) & $\mathrm{OR}(95 \% \mathrm{Cl})$ & $P$ value \\
\hline 3 & 12 & 3 & 25.00 & $0.78(0.21,2.88)$ & 0.707 \\
\hline 4 or more & 18 & 4 & 22.22 & $0.67(0.22,2.03)$ & 0.476 \\
\hline \multicolumn{6}{|c|}{ Consume solid/semisolid food and frequencies } \\
\hline 0 & 329 & 99 & 30.09 & 1 & \\
\hline 1 to 2 & 1289 & 410 & 31.81 & $1.08(0.83,1.41)$ & 0.550 \\
\hline 3 & 1715 & 515 & 30.03 & $0.99(0.77,1.29)$ & 0.982 \\
\hline 4 or more & 1117 & 299 & 26.77 & $0.85(0.65,1.11)$ & 0.236 \\
\hline \multicolumn{6}{|c|}{ Consume nutrient sachet and frequencies } \\
\hline 0 & 1773 & 581 & 32.77 & 1 & \\
\hline 1 to 2 & 302 & 115 & 38.08 & $1.26(0.98,1.62)$ & 0.071 \\
\hline 3 & 201 & 69 & 34.33 & $1.07(0.79,1.46)$ & 0.656 \\
\hline 4 or more & 2174 & 558 & 25.67 & $0.71(0.62,0.81)$ & $<0.001$ \\
\hline \multicolumn{6}{|c|}{$\begin{array}{l}\text { Is able identify the optimum timing of } \\
\text { complementary feeding }\end{array}$} \\
\hline No & 2483 & 697 & 28.07 & 1 & \\
\hline Yes & 1967 & 626 & 31.83 & $1.20(1.05,1.36)$ & 0.007 \\
\hline \multicolumn{6}{|c|}{$\begin{array}{l}\text { Is able identify to the first complementary } \\
\text { food which should be consumed by infants }\end{array}$} \\
\hline No & 4225 & 1246 & 29.49 & 1 & \\
\hline Yes & 225 & 77 & 34.22 & $1.24(0.94,1.65)$ & 0.131 \\
\hline \multicolumn{6}{|c|}{$\begin{array}{l}\text { Has know the optimum food of } \\
\text { supplementary iron }\end{array}$} \\
\hline No & 3185 & 939 & 29.48 & 1 & \\
\hline Yes & 1265 & 384 & 30.36 & $1.04(0.91,1.20)$ & 0.565 \\
\hline \multicolumn{6}{|c|}{ Is able identify nutrient relate to anemia } \\
\hline No & 2522 & 772 & 30.61 & 1 & \\
\hline Yes & 1928 & 551 & 28.58 & $0.91(0.80,1.03)$ & 0.142 \\
\hline \multicolumn{6}{|c|}{$\begin{array}{l}\text { Is able identify the optimum timing of } \\
\text { breastfeeding }\end{array}$} \\
\hline No & 3852 & 1151 & 29.88 & 1 & \\
\hline Yes & 598 & 172 & 28.76 & $0.95(0.78,1.145)$ & 0.578 \\
\hline
\end{tabular}

In our study, breastfeeding in the previous $24 \mathrm{~h}$ had a marked effect on the prevalence of anemia. A Chinese birth cohort study of the association between the duration of exclusive breastfeeding and infant anemia found that exclusive breastfeeding for 6 months was associated with an increased risk of anemia in infants 12 months of age [24]. The concentration of iron in human milk is relatively low, and so iron is supplied mainly from iron stores from birth until 6 months of age. However, iron stores are depleted after 6 months of age, the time at which iron demand increases because of rapid growth and development [25]. Therefore, the risk of anemia increases after 6 months of age in breastfed children; indeed, their risk is higher than that of children 18 to 23 months of age. Anemia in children 6 months of age is ameliorated by the intake of iron-rich foods, and their risk of anemia increases with age $[19,26]$.
Addition of milk powder or infant formula was associated with a decreased risk of anemia, likely because these have higher levels of minerals than breast milk. The production of powdered formulas was base on ordinary powdered, as iron has been added to powdered formulas to prevent anemia in recent decades [27].

Addition of a nutrient sachet four or more times in the previous week was significantly negatively associated with anemia. In rural areas of China, soybean powder-based micronutrient supplements (nutrient sachets) significantly reduced the burden of anemia among children 6 to 23 months of age. Consumption of four nutrient sachets weekly by infants is recommended in China. In this study, the risk of anemia in the $48.85 \%$ of the children who consumed a nutrient sachet four or more times weekly was $30 \%$ lower than that of those who did not consume any 
Table 6 Multivariate regression analysis of anemia among children 6 to 23 months of age

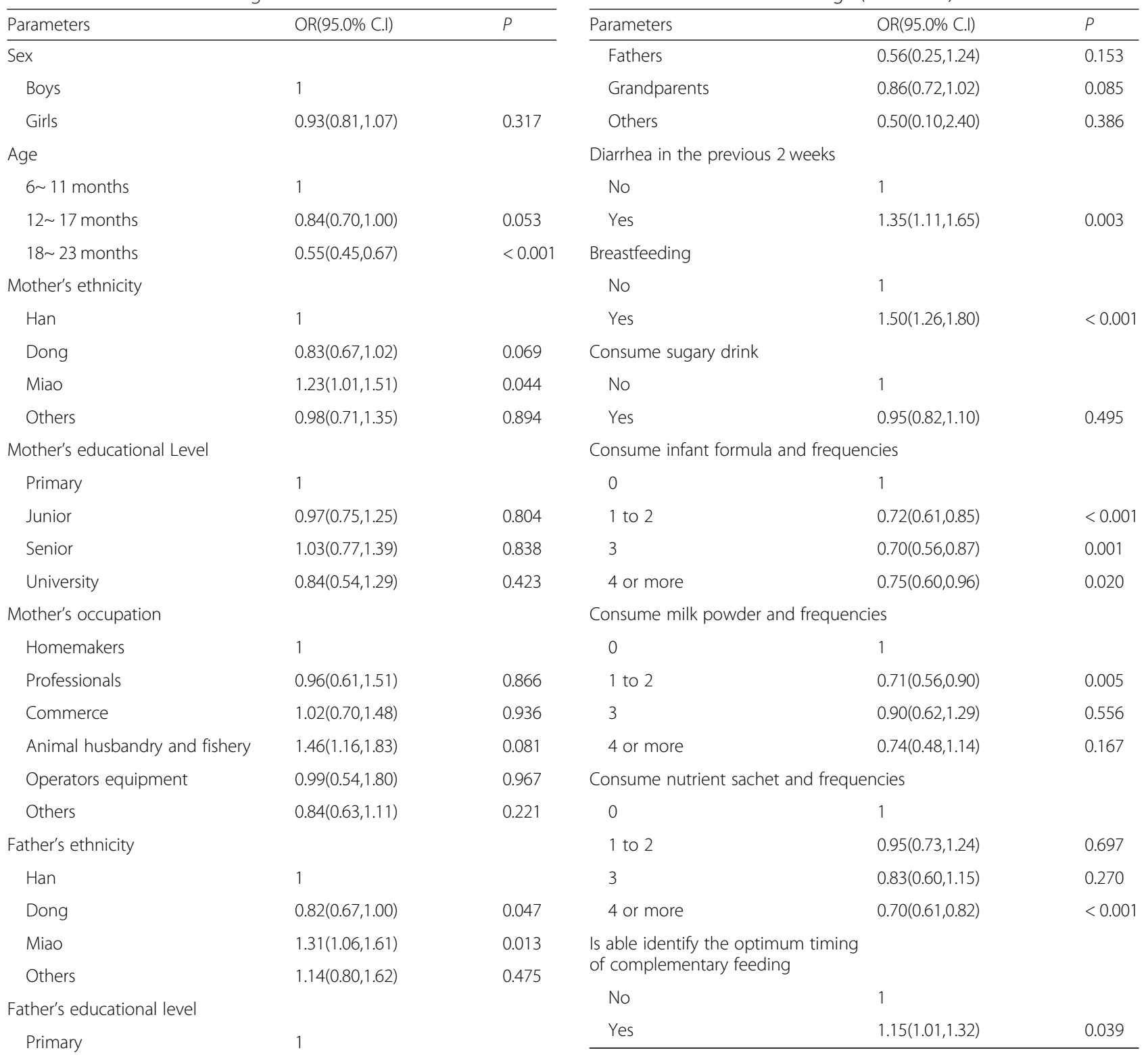

$0.85(0.65,1.13) \quad 0.266$ $0.86(0.63,1.18) \quad 0.339$

$0.79(0.52,1.19) \quad 0.257$

University

Father's occupation

Homemakers

Professionals

Commerce

Animal husbandry and fishery

Operators equipment

Others

Caregiver's groups

Mothers
Table 6 Multivariate regression analysis of anemia among children 6 to 23 months of age (Continued)

Diarrhea in the previous 2 weeks

Consume infant formula and frequencies

$0.72(0.61,0.85)<0.00$

4 or more $\quad 0.75(0.60,0.96) \quad 0.020$

Consume milk powder and frequencies

nutrient sachets. Zhouxun reported that the child's age and ethnicity, the parents' education and occupation, and adverse reactions to Yingyangbao were associated with taking Yingyangbao among children 6 to 23 months of age in poor rural areas of Hunan Province, China [28]. Therefore, provision of nutrient sachets reduced the burden of anemia among children in Huaihua; however, its implementation is unsatisfactory.

In this study, having parents of Miao ethnicity was associated with an increased risk of anemia, and a father of Dong ethnicity with a reduced risk of anemia. This is in agreement with several prior reports. For example, Luoyan reported that the prevalence of anemia in children of Kazakh ethnicity is higher than in those of Han 
ethnicity, which is likely due to the unique habitats and customs of minority ethnicities [29]. Therefore, health education in areas inhabited by minority ethnicities needs to be strengthened. In Yunnan Province, the risk of anemia among children of $\mathrm{Li}$ ethnicity is 1.9-fold greater than that of those of Han ethnicity due to Mediterranean anemia [30].

Of the children, 12.20 and $18.58 \%$ had experienced diarrhea and fever in the previous 2 weeks. Wuxiao-jian reported that the 2-week prevalence of diarrhea and fever among children less than 3 years of age is associated with socioeconomic status, healthcare during pregnancy and the puerperal period, and mothers' knowledge of disease prevention [31]. Children with a history of diarrhea during the past 2 weeks were more likely to be anemic than children without diarrhea because of loss of appetite and malabsorption of nutrients in the intestine. Similar findings have been reported by studies conducted in Indonesia [32, 33].

The ability of the caregiver to identify the optimum timing of complementary feeding increased the risk of anemia in this study. Caregivers' level of knowledge of nutrition and feeding may influence the feeding behavior of children [34, 35]. Although $44.20 \%$ of the caregivers were able identify the optimum timing of complementary feeding, only $5.06 \%$ were able identify to first complementary food which should be consumed by infants. A lack of knowledge of feeding practices among caregivers may explain the link between their ability to identify the optimum timing of complementary feeding and the risk of anemia.

This study had several limitations that should be taken into consideration. The cross-sectional design of this study prevents determination of the causality of the associations of factors with anemia. Further, the lack of information on family income, prenatal maternal anemia status, birth interval, and the timing of complementary feeding hampered analysis of the factors associated with anemia in children 6-23 months of age. However, this study involved 4500 children in a large geographic area (six regions of Huaihua), and considered caregivers' knowledge of feeding practices and nutrition. Our findings clarify the prevalence and risk factors of anemia among children 6-23 months of age in Huaihua, and will facilitate the development of countermeasures to reduce the burden of anemia.

\section{Conclusions}

In conclusion, the prevalence of anemia among children 6 to 23 months of age in Huaihua was higher than that in more developed regions of China, and represents a considerable healthcare burden. The feeding practice of caregivers was associated with anemia. In addition, diarrhea, parents' ethnicity, and caregivers' level of knowledge of nutrition were associated with anemia. Therefore, nutrition improvement projects are needed to reduce the burden of anemia among children in Huaihua.

\section{Abbreviations}

AOR: Adjusted odds ratio; Cl: Confidence interval; COR: Crude odds ratio

\section{Acknowledgements}

We would like to thank maternal and child health care hospital of Yuangling, Mangyang, Xupu, Chenxi, Zhijiang, Huitong, Xinghuang to collected the data.

\section{Funding}

Self-funded.

\section{Availability of data and materials}

The datasets used and/or analyzed during the current study are available from the corresponding author on reasonable request.

\section{Authors' contributions}

$\mathrm{ZH}, \mathrm{FJ}$ and $J \mathrm{~L}$ conceived the research idea. $\mathrm{ZH}$ collected the data, performed the statistical analyses and drafted the manuscript. TX, DJ and JZ participated in data acquisition, analysis, and reviewed the draft manuscript. FJ and $\mathrm{J}$ provided the critical review of the manuscript. All authors approved the final version.

\section{Ethics approval and consent to participate}

Informed consent was signed by caregiver of children before the interview. The project was approved by Huaihua Women's Federation and Municipal Commission of Health and Family Planning (No. 201563).

Consent for publication

Not applicable.

\section{Competing interests}

The authors declare that they have no competing interests.

\section{Publisher's Note}

Springer Nature remains neutral with regard to jurisdictional claims in published maps and institutional affiliations.

\section{Author details}

${ }^{1}$ Hunan University of Medicine, No. 492 Jinxi South Road, Huaihua 418000, Hunan, China. ${ }^{2}$ Huaihua Maternal and Child Health Care Hospital, Huaihua, China.

Received: 15 March 2018 Accepted: 8 November 2018

Published online: 19 November 2018

\section{References}

1. World Health Organization, Vitamin and mineral nutrition/Anemia, 2011.

2. World Health Organization. The global prevalence of anemia in 2011. Geneva: World Health Organization; 2015.

3. Benoist BD, Cogswell EM MLEI, Wojdyla D. Worldwide Prevalence of Anemia 1993-2005: WHO Global Database on Anemia. Geneva: World Health Organization; 2008.

4. Mclean E, Cogswell M, .Egli I, Wojdyla D, Debenoist B. "Worldwide prevalence of anemia, WHO vitamin and mineral nutrition information system, 1993-2005". Public Health Nutr 2009; 12(4):444-454.

5. Ministry of Health. The Nutrition Development Report of Chinese Children Aged 0-6 (2012). Beijing: Ministry of Health; 2012.

6. Thankachan P, Muthayya S, Walczyk T, Kurpad AV, Hurrell RF. An analysis of the etiology of anemia and iron deficiency in young women of low socioeconomic status in Bangalore, India. Food Nutr Bull. 2007;28:328-36.

7. Pollitt E. Early iron deficiency anemia and later mental retardation. Am J Clin Nutr. 1999;69(1):4-5.

8. Cusick SE, Georgieff MK. The role of nutrition in brain development: the golden opportunity of the "first 1,000 days". J Pediatr. 2016;175:16-21.

9. Carter RC, Jacobson JL, Burden MJ. Iron deficiency anemia and cognitive function in infancy. Pediatrics. 2010;126:427-34.

10. Victora CG, Adair L, Fall C. Maternal and child under-nutrition: consequences for adult health and human capital. Te Lancet. 2008;371:340-57. 
11. Hipgrave DB, Fu X, Zhou H, Jin Y, Wang X, Chang S, Scherpbier RW, Wang $Y$, Guo S. Poor complementary feeding practices and high anemia prevalence among infants and young children in rural central and western China. Eur J Clin Nutr. 2014:68:916-24.

12. Dong $C X$, Ge PF, Zhang CJ, Ren XL, Fan HQ, Zhang YR ZJ, Xi JE. Effects of different feeding practices at 0-6 months and living economic conditions on anemia prevalence of infants and young children. J Hyg Res. 2013;42: 596-9 (in Chinese).

13. Pasricha SR, Black J, Muthayyaetal S. Determinants of anemia among young children in rural India. Pediatrics. 2010;126(1):e140-9.

14. Desalegn A, Mossie A, Gedefaw L, Schooling CM. Nutritional iron deficiency anemia: magnitude and its predictors among school age children, Southwest Ethiopia: a community based cross-sectional study. PLoS One. 2014;9(12):e114059.

15. Shet A, Mehta S, Rajagopalan N. Anemia and growth failure among HIVinfected children in India: a retrospective analysis. BMC Pediatr. 2009;9:37.

16. Huo JS, Sun J, Fang Z. Effect of home-based complementary food fortification on prevalence of on anemia among infants and young children aged 6 to 23 months in rural poor region of China[J]. Food Nutr Bull. 2015; 36(4):405-14.

17. Sun QN, Sun J, Jia XD. The intervention effect of community-based complementary food supplement (Ying yang bao) to infants and young children in China: a review. J Hyg Res. 2015;44(6):970-7.

18. Yuang $X$, Run SJ, Duan JH. The anemia status of children aged 0 to 6 years from 1998 to 2007 in Beijing. Chinese Journal of Child and Woman Health Research. 2010;21(4):412-4 In Chinese

19. Wang $L$, Su XG, Wang $C$. The status of anemia and associated factors among children under 3 years in 4 provinces rural of central and Western China. Chinese Journal Health Education. 2013;29(5):390-3 (In Chinese).

20. Xu YY. Malnutrition and anemia among children under 3 years in Tibetan Autonomous Prefecture of Yushu in 2012. Chinese Journal of Child Health Care. 2013;23(9):986-8 (In Chinese).

21. Engle-Stone R, Aaron GJ, Huang J, Wirth JP, Namaste SM, Williams AM Predictors of anemia in preschool children: biomarkers reflecting inflammation and nutritional determinants of Anemia (BRINDA) project. Am J Clin Nutr. 2017:106:402S-15S.

22. Carla C. Iron Nutriture of the fetus, neonate, infant, and Child. Ann Nutr Metab. 2017;71(suppl 3):8-14.

23. Domellöf M, Braegger C, Campoy C. Iron requirements of infants and toddlers. J Pediatr Gastroenterol Nutr. 2014;58(1):119-29.

24. Wang FL, Liu HJ, Prolonged Exclusive WY, Breastfeeding Duration I. Positively associated with risk of Anemia in infants aged 12Months. J Nutr. 2016;146:1707-13.

25. Tsai SF, Chen SJ, Yen HJ, Hung GY, Tsao PC, Jeng MJ, Lee YS, Soong WJ, Tang RB. Iron deficiency anemia in predominantly breastfed young children. Pediatr Neonatol. 2014;55:466-9.

26. Joo EY, Kim KY, Kim DH, Lee JE, Kim SK. Iron deficiency anemia in infants and toddler. Blood Res. 2016;51:268-73.

27. Wang SP, Ren FZ, Luo J, Peng HX, Wang YH. Progress in infant formula Milk powder. Transactions of the Chinese Society for Agricultural Machinery. 2015;46(4):200-10 (In Chinese).

28. Zhou X, Fang JQ, Luo JY, Wang H, Du QY. Factors associated with taking Yingyangbao efficiently among Infants Young Child aged 6-24 months in poor rural areas of Hunan Province,China. J Hyg research. 2017;46(2):256-61 In Chinese.

29. Luo Y Zhou P. Analysis on the causes of nutritional iron deficiency anemia in one year old children of Kazak nationality. Maternal and Child Health Care of China. 2011;26(23):3575-7 (In Chinese).

30. Zu HP, Rao YH, Pan LC, Huang WM, Fang WM, Wu Y, Du YK. Analysis on the current situation and effect factors of anemia among the children under six years in rural areas of Hainan province. Maternal and Child Health Care of China. 2012;27(6):886-9 (In Chinese).

31. Wu XJ. The two-week prevalence rates and risk factors of common cold and diarrhoea for children under 3 across 45 countries of western China. Master thesis, the Chinese Center for Disease Control and. Prevention. 2008; In Chinese.

32. Semba RD, Pee S, Ricks MO, Sari M, Bloem MW. Diarrhea and fever as risk factors for anemia among children under age five living in urban slum areas of Indonesia. Int J Infect Dis. 2008;12(1):62-70.

33. Howard CT, Pee S, Sari M, Bloem MW, Semba RD. Association of diarrhea with anemia among children under age five living in rural areas of Indonesia. J Trop Pediatr. 2007;53(4):238-44.
34. Zeng R, Luo JY, Tan C, Du QY, Zhang WM, Li YP. Relationship between caregivers' nutritional knowledge and children's dietary behavior in Chinese rural areas. J Cent South Univ. 2012;37(11):1097-103 (In Chinese).

35. Gui XC, Ju KM. Relationship between the nutrition knowledge level of parents and nutritional status of their children in Shanghai. Chinese Journal of School Health. 2003;24(6):755-6 (In Chinese).
Ready to submit your research? Choose BMC and benefit from:

- fast, convenient online submission

- thorough peer review by experienced researchers in your field

- rapid publication on acceptance

- support for research data, including large and complex data types

- gold Open Access which fosters wider collaboration and increased citations

- maximum visibility for your research: over $100 \mathrm{M}$ website views per year

At BMC, research is always in progress.

Learn more biomedcentral.com/submissions 